\title{
3D Imaging of Titanium Alloys Multi-Layered Structures (MLS) Via X-Ray Microscopy
}

\author{
S.V. Prikhodko ${ }^{1}$, M.Norouzi Rad ${ }^{2}$, P.E.Markovsky ${ }^{3}$, D.G. Savvakin ${ }^{3}$, N. Julian ${ }^{1}$ and O.M.Ivasishin ${ }^{3}$ \\ 1. Department of Materials Science and Engineering, UCLA, Los Angeles, CA. \\ 2. Carl Zeiss Microscopy LLC., Pleasanton, CA. \\ 3. G.V. Kurdyumov Institute for Metal Physics, National Academy of Science of Ukraine, Kiev, Ukraine
}

The progress in scientific research and technology greatly depends upon effective imaging solutions for characterizing the properties of materials, revealing details of microstructure, ideally in 3-D. X-ray microscopy (XRM) that has become available in the past few decades provides non-destructive 3-D imaging capabilities on a broad range of materials at different scales, observing features with sizes spanning from nanometers to millimeters. Commercially available XRM systems can be divided into three major classes: 1) conventional X-ray micro-computed tomography ( $\mu \mathrm{CT}$ ) instrumentation; 2) submicron resolution XRM; and 3) nanoscale XRM [1]. Here we present our results on characterization of multi-phase, multi-layered structures (MLS) consisted of titanium-based alloys and composites using submicron resolution XRM, Versa 520 (Zeiss). Our study involves correlative analysis using optical microscopy, SEM, Nova 230 (FEI) and EDS and WDS spectroscopies.

Several MLS of Ti-based alloys were fabricated using proprietary powder metallurgy approach based on use of hydrogenated titanium, $\mathrm{TiH}_{2}$ [2]. $\mathrm{TiH}_{2}$ powder (particles size smaller than $\sim 100 \mu \mathrm{m}$ ) was blended with corresponding amount of elemental powders of alloying additives (metals and master alloys) to form required compositions and pressed to a green preforms. Whenever titanium composites with inclusions of the strengthening phases, such as $\mathrm{TiB}$ or $\mathrm{TiC}$ were needed their powders were added at required amount to the blends. In order to obtain $\mathrm{TiB}$ inclusions as a part of composite we used $\mathrm{TiB}_{2}$ powder which expected to chemically transform during the sintering following the reaction: $\mathrm{TiB}_{2}+\mathrm{Ti}=2 \mathrm{TiB}$. Preforms were pressed in dies at $150 \mathrm{MPa}$ and vacuum furnace heated $\left(1250{ }^{\circ} \mathrm{C}, 3-4 \mathrm{~h}\right)$. That provided dehydrogenation of titanium, sintering of powders to form bulk plates $(90 \times 90 \times 15 \mathrm{~mm})$ and formation of uniform alloy or composite within each layer of the plates. Alloys composition measured by XRF, EDS and WDS was found to be in compliance with expected compositions. MLS structures were characterized using optical microscopy, SEM, EBSD and TEM. Our results show that the grain size of the alloys is about $100 \mu \mathrm{m}$ and porosity varies in the range 2-9\%. SEM backscattered electron images show presence of two distinctive inclusion morphologies for the alloys with TiB particles: needles and irregular/globular (Fig.1, C and D correspondingly). Chemical analysis suggests that irregular shape inclusions are due to not completely transformed $\mathrm{TiB}_{2}$ during the sintering process whereas needle shape inclusions are indeed completely transformed $\mathrm{TiB}_{2}$ which forms TiB. XRM were performed for non-destructive 3D imaging of internal structure of the alloys to reveal pores configuration and different phases arrangement. Samples were prepared in the shape of pillars with diameters of $\sim 1.7 \mathrm{~mm}$ and scanned in Full Field at $3.5 \mu \mathrm{m} /$ voxel (at $80 \mathrm{kV}$ and 7 Watts) and High Resolution interior topographies were done at $0.7 \mu \mathrm{m} / \mathrm{voxel}$ (at $70 \mathrm{kV}$ and 6 watts). Samples were then trimmed further down to $\sim 0.6 \mathrm{~mm}$ and were scanned at $0.4 \mu \mathrm{m} /$ voxel resolution (with $50 \mathrm{kV}$ and 4 Watts). Results on XRM are in good agreement with our SEM, EBSD and TEM study. Beside XRM reviles the details on structures impossible with traditional 2D observation of real 3D configurations. It is obvious that this technique can bring to some cutting-edge results on our materials. 
References:

[1] A.P.Merkle and J.Gelb, Microscopy Today (2013), p. 10.

[2] O.M.Ivasishin, V.S.Moxson. In: Ma Qian and F.H. Froes (Eds.) "Titanium Powder Metallurgy: Past, Present and Future", (Elsevier) 2014.

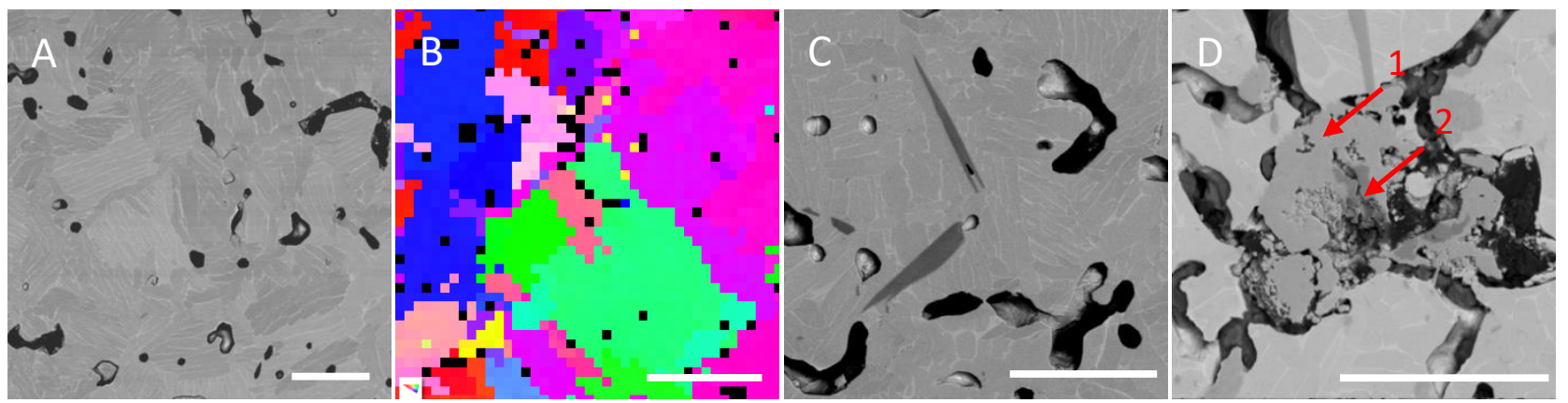

Figure 1. Images show results on the SEM analysis of Bi-Layered Ti-6Al-4V / Ti-6Al-4V +8.3\% TiB MLC sample after the sintering: backscattered electron images (A, C, D,) and EBSD (B). Scale bar on all images is $50 \mu \mathrm{m}$. Image $\mathrm{D}$ shows presence of $\mathrm{TiB}(1)$ and $\mathrm{TiB}_{2}(2)$ phases within globular/irregular shape inclusion.

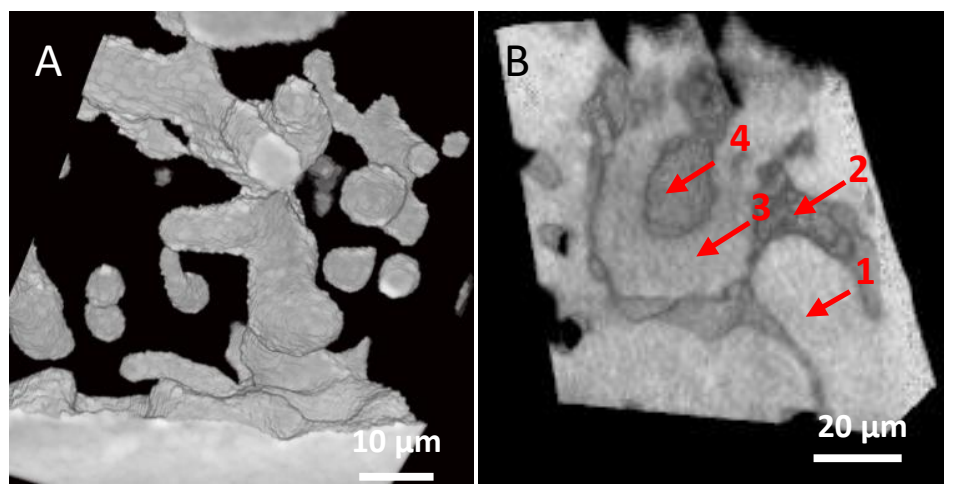

Figure 2. XRM analysis of Bi-Layered MLS sample of $\mathrm{Ti}(\mathrm{CP}) / \mathrm{Ti}(\mathrm{CP})+8.3 \% \mathrm{TiB}$. A. 3D pore reconstruction. $\mathrm{B}$. Internal virtual slice of the structure in the vicinity of inclusion revealing 4 different phases: Ti-1; pore -2 ; TiB $-3 ; \mathrm{TiB}_{2}-4$. Image $\mathrm{B}$ confirms that there is a volume inside the inclusion (4) where $\mathrm{TiB}_{2}$ stays untransformed during sintering, whereas the outer inclusion layer (3) is a region of completely transformed into TiB solid.

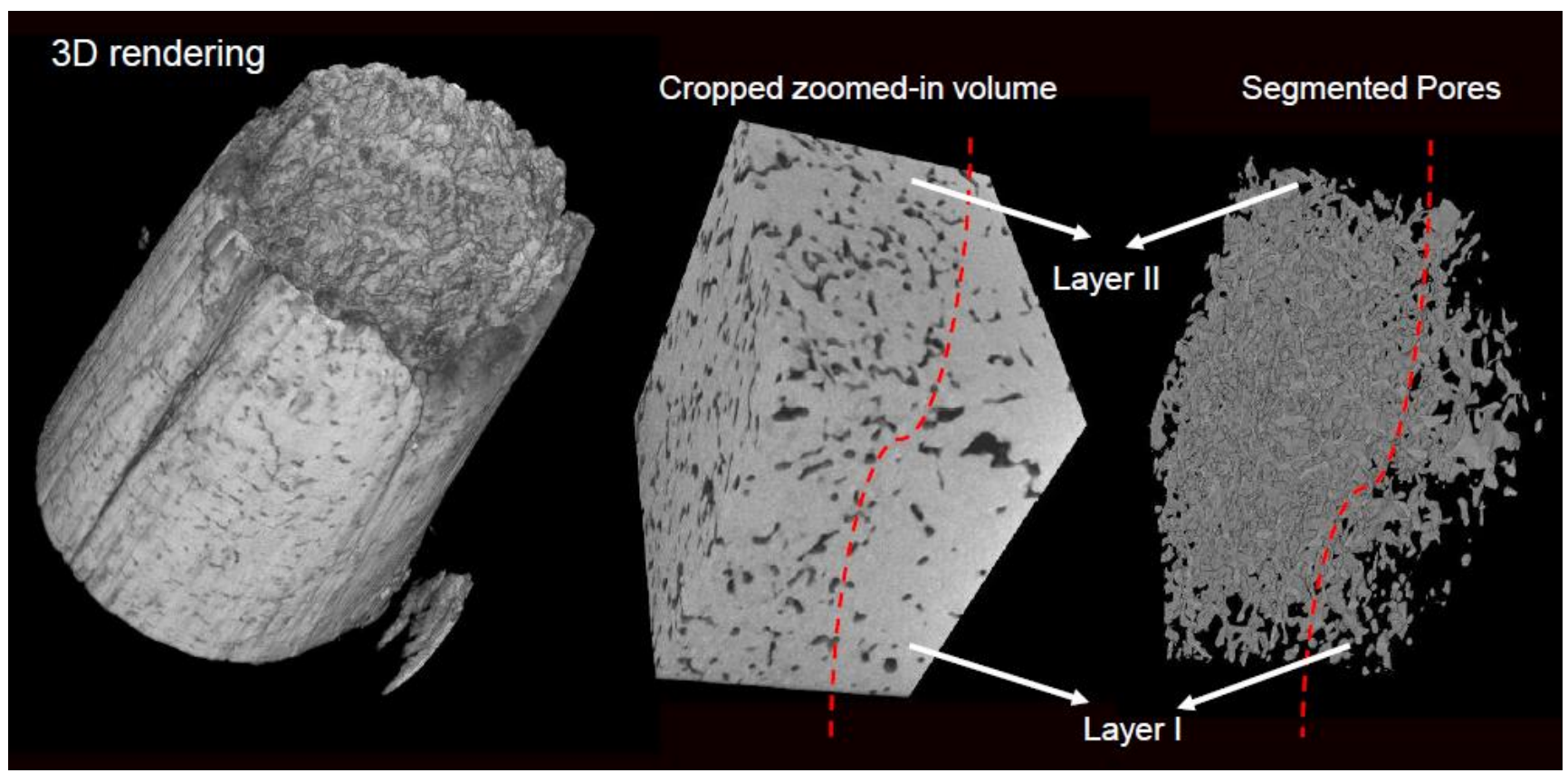

Figure 3. Pore space segmentation of Bi-Layered MLS sample of Ti (CP) / Ti (CP)+8.3\% TiB using X-ray XRM Versa 520. Diameter of the sample at the tip is $\sim 0.62 \mathrm{~mm}$. Sample HR $(0.4$ $\mu \mathrm{m} /$ voxel). 